\title{
Abordagem sobre as técnicas de geoprocessamento aplicadas ao planejamento e gestão urbana
}

\section{An approach on geoprocessing tools applied to planning and urban management}

\author{
Flávia C. Farina ${ }^{1}$
}

\section{Resumo}

Nas últimas décadas, as discussões em torno do tema urbanização têm enfatizado a preocupação com o meio ambiente, a renovação dos instrumentos tradicionais de planejamento urbano e a necessidade de utilização de novas técnicas para monitorar e avaliar a expansão urbana. Este estudo visa contribuir para o planejamento e gestão da ocupação urbana, demonstrando as possibilidades técnicas de melhor organizar a expansão territorial das cidades, observados critérios ambientais. Neste sentido, são feitas considerações sobre a evolução dos métodos de planejamento e a inserção da variável ambiental na gestão urbana. São expostas algumas contribuições das técnicas de geoprocessamento como ferramenta para auxiliar no problema da expansão urbana. A utilização das técnicas de geoprocessamento propicia eficiência na obtenção, armazenamento, atualização, recuperação e cruzamento dos dados necessários à gestão urbana. Os resultados demonstram que a utilização dessas técnicas é eficaz para o levantamento dos recursos naturais e das atividades humanas, desenvolvimento de banco de dados ambientais georreferenciado, monitoramento das transformações ambientais e planejamento do uso e ocupação territorial.

Palavras-chave: geoprocessamento; planejamento urbano; meio ambiente.

\begin{abstract}
In the past decades, debates about urbanization highlight the concern with the environment, the renewal of traditional tools for urban planning, and the need to use new techniques in order to monitor and assess urban expansion. The utilization of Geoinformatic techniques made the obtainment, storage, updating, recovery, and crossing of the data efficient. The results show that the use of these techniques is efficient in the survey of natural resources and human activities, development of environmental georeferred databanks, monitoring of environmental changes, and planning of land use and occupation.
\end{abstract}

Key words: geoinformatic; urban planning; environment.

\section{Introdução}

O meio físico é o suporte às atividades humanas. É a partir da apropriação e transformação da natureza intocada que o homem produz as condições para sua reprodução. O homem integra-se e interage com a natureza, transformando-a e adaptando-a às suas necessidades. No entanto, a produção da paisagem geográfica, sobretudo pela urbanização e industrialização sem limites, não tem sido harmônica, criando-se uma situação de conflito entre os usos estabelecidos pelo homem e a aptidão do ambiente natural. A consequiência dessa relação é mais evidente nas cidades, refletindo-se na ocupação do espaço e na organização do território.

\footnotetext{
1 Doutoranda em Geociências pela Universidade Federal do Rio Grande do Sul. Professora Assistente e Coordenadora do Curso de Engenharia Ambiental do Centro Universitário La Salle - UNILASALLE. Endereço: Av. Victor Barreto, 2288 - Canoas -RS - Brasil - CEP 92010-000. E-mail: ffarina@unilasalle.edu.br.

Artigo recebido em novembro de 2006 e aprovado para publicação em dezembro de 2006.
} 
Em um primeiro momento, podemos afirmar que a racionalidade do modelo de urbanização é a ocupação dos espaços, priorizando o desenvolvimento econômico e social em detrimento da preservação dos ecossistemas e da socialização dos benefícios do desenvolvimento, provocando, nas cidades, o acúmulo de problemas socioambientais, tais como a expansão urbana e a construção de infra-estruturas sobre áreas inadequadas, a poluição dos recursos hídricos pela instalação de indústrias, a invasão de áreas ecologicamente sensíveis pela população de baixa renda, entre outros. Assim, os centros urbanos apresentam-se, simultaneamente, como locus do capital, da modernidade, da cultura, da comunicação e, também, das desigualdades sociais, da miséria, do desemprego, da especulação imobiliária e dos conflitos ambientais.

Podemos afirmar, também, que o modelo de planejamento adotado até há pouco tempo pelos municípios é parcial, fragmentado e que está condicionado a, apenas, localizar usos do solo e a projetar a infra-estrutura.

Atualmente, o forte dinamismo do entorno geopolítico, social, econômico, tecnológico e administrativo está produzindo implicações de grande magnitude para o desenvolvimento urbano. Essas implicações, por sua vez, obrigam a transformação e renovação dos instrumentos tradicionais de planejamento urbano. As propostas de planejamento físico-territorial representam uma das últimas mudanças culturais no conceito de planejamento, em grande parte, devido ao surgimento do movimento ecológico. Em todo o mundo, o movimento ambientalista encontra-se, em grande medida, no cerne de uma reversão drástica das formas pelas quais pensamos a relação entre economia, sociedade e natureza, propiciando, assim, o desenvolvimento de uma nova cultura. $\mathrm{O}$ objetivo do planejamento passa a ser, então, alcançar um maior desenvolvimento econômico e uma melhor qualidade de vida, considerando a dimensão física do território, mas, igualmente, contemplar a questão ambiental e a complexidade socioeconômica e política da comunidade, minimizando, assim, as contradições e fraturas habituais nos planos setoriais. (CASTELLS, 1999; GUELL 1997).

\section{Geoprocessamento}

O grande instrumento viabilizador da nova proposta de planejamento é o desenvolvimento das técnicas de geração e análise de informação espacial, ou seja, as técnicas de geoprocessamento. Essas técnicas permitem superar a visão parcial que o homem tem do mundo, através da capacidade de conhecer e acompanhar o movimento da natureza e da sociedade, e integrar as mais diversas fontes de informação, fornecendo as bases científicas para um novo plano de desenvolvimento urbano.

O sensoriamento remoto e a aerofotogrametria, por meio da geração de imagens da superfície terrestre, propiciam uma grande fonte de informações imprescindíveis ao conhecimento e à evolução da realidade urbana. As técnicas de sensoriamento remoto permitem, através de uma série de funções, que essas imagens sejam processadas, analisadas e interpretadas, gerando mapeamentos e quantificações.

A função dos sistemas de informação geográfica (SIG) consiste em integrar as informações obtidas por sensoriamento remoto com outros dados espacialmente distribuídos (modelo numérico do terreno e declividade, entre outros). Os SIG permitem, dessa forma, criar um modelo do mundo real ao integrarem dados de natureza diversa, voltados para uma aplicação em particular. Barredo (1996) sugere que, atualmente, a alta diversificação da informação espacial e o grande volume de dados espaciais gerados pelo sensoriamento remoto tornam os SIG uma potente ferramenta de gestão desses dados.

No entanto, realizada a gestão adequada dos dados espaciais, podemos pensar que a ordenação territorial e, em particular, os múltiplos aspectos do planejamento físico-territorial, podem ser assistidos pelos SIG. Contudo, quando se delineiam os problemas freqüentes na ordenação territorial como onde, quanto, a que distância e quais, surge a necessidade de integrar ferramentas alheias aos SIG para respondê-los. Tais ferramentas podem ser para um sem fim de propósitos, as técnicas de avaliação multicritério (AMC).

Bosque (1997) avalia que as funções analíticas dos SIG e a integração com as técnicas AMC as convertem em uma máquina de simulação, permitindo introduzir conhecimento objetivo e/ou heurístico. Assim, os planejadores e administradores podem ter uma impressão de qual pode ser o resultado, no território, de suas decisões, ou gerar diferentes cenários virtuais, para avaliar a implementação de políticas ou medidas de planejamento. Nesse 
sentido, essas novas técnicas assumem relevância, pois auxiliam no processo racional de tomada de decisão, na previsão e controle do uso do solo, mediante uma adequada distribuição das atividades no território, compatíveis com a conservação do patrimônio físico.

Portanto, as possibilidades de utilização das técnicas expostas e a necessidade do desenvolvimento urbano compatível com a preservação ambiental podem estabelecer as formas a partir das quais as técnicas de geoprocessamento auxiliarão na definição de áreas adequadas à implantação e gestão de atividades urbanas.

Da perspectiva da gestão dos espaços urbanos, a questão do planejamento resgata a unidade homem/natureza. A organização territorial da sociedade envolve duas dimensões da reprodução social: as relações sociais e as relações entre sociedade e natureza que as práticas sociais causam. As relações sociais vigentes, nesse sentido, regem não apenas as relações entre os diferentes grupos e indivíduos da sociedade, mas, igualmente, as relações de interação a serem estabelecidas entre eles, como sociedade organizada e a natureza, originária ou transformada pela própria ação humana. A ausência dessa visão integradora na formulação de projetos de desenvolvimento urbano e nos processos de tomada de decisões é, em grande medida, responsável pela ação contra o meio ambiente observada, na atualidade, em muitos municípios.

A estratégia de crescimento urbano, adotada pelos municípios, geralmente privilegia os critérios de produtividade dos equipamentos coletivos, a viabilidade econômica e a disponibilização de áreas inadequadas, de acordo com interesses hegemônicos. Através deste trabalho, procura-se mostrar que é possível incluir a variável ambiental.

O aperfeiçoamento crescente dos SIG e a automação dos procedimentos administrativos permitem estabelecer o processo de urbanização, com instrumentos cada vez mais sofisticados, que facilitam a tomada de decisões sobre operações urbanísticas com um elevado grau de complexidade. Aliado a esse processo de modernização, é preciso, ainda, transcender o planejamento setorial das cidades, que tem impedido a obtenção de uma visão global de suas problemáticas e a formulação de um modelo integrado para seu desenvolvimento futuro.

As técnicas de geoprocessamento certamente fornecerão subsídios básicos a cenários urbanos sustentáveis para a sociedade, bem como fornecerão as diretrizes fundamentais para estabelecer os meios de adoção de políticas que possam implementar uma melhor qualidade ambiental para o presente e para o futuro.

\section{Desenvolvimento urbano}

O desenvolvimento econômico que marcou profundamente a era industrial representou um modelo caracterizado por impactos ao equilíbrio ambiental. Tanto o processo produtivo quanto o desordenado crescimento urbano não tiveram qualquer tipo de regulamentação que pudesse compatibilizar a natureza com a sociedade. Somente nas últimas décadas do século XX é que as preocupações com o meio ambiente ganharam força, impulsionadas pelos movimentos ecológicos.

$\mathrm{Na}$ atualidade, embora a ênfase do processo produtivo global seja dada ao mercado e à maximização dos lucros, o controle sobre as áreas de expansão industrial e urbana é maior. Os municípios, os estados e a União dispõem de mecanismos reguladores e de agências especializadas em políticas de compatibilidade do desenvolvimento com a preservação dos ecossistemas naturais. A poderosa expansão do poder emergente dos interesses multinacionais, quanto ao processo produtivo, encontra uma contraposição ambiental, sustentada não só pelos organismos oficiais, como, principalmente, pelos que representam o terceiro setor, destacando-se as ONGs, as fundações e os movimentos populares.

A natureza, seus ecossistemas e sua biodiversidade não podem ficar submetidos apenas aos interesses do mercado. As atividades econômicas, em crescente expansão, vêm tornando a sociedade e a natureza reféns das estratégias do mercado e do fluxo incessante de mudanças tecnológicas e espaciais, como afirma Touraine (1994). Para o autor citado, a desordem da sociedade, identificada pelos profundos desequilíbrios sociais e ambientais, choca-se com os desejos e as identidades de um desenvolvimento harmônico. Numa dimensão mais ampla, a diversidade que caracteriza a natureza é base para a estabilidade ecológica e oferece sustentação às diversas formas de vida e culturas. A concepção de que a natureza é separada do homem e por ele subjugada, 
vinculada à racionalidade do sistema capitalista, colocou em desequilíbrio o desenvolvimento das sociedades e a preservação dos ambientes naturais.

O advento da tecnologia mecânica, que impulsionou a Revolução Industrial, e da tecnologia microeletrônica, que iniciou a era pós-industrial (informacional), produziu espaços diferenciados de produção e de expansão urbana, embora, tenha gerado níveis de padronização em relação aos aspectos negativos da evolução social e da preservação ambiental. O tempo, nesse processo, é o do capital e não o tempo da natureza, ou ambos conectados; a lógica não é a do desenvolvimento da sociedade como um todo, mas da dominância da razão instrumental, que leva à especulação financeira, à organização da escassez e ao aprofundamento das dependências, enfraquecendo o poder dos Estados-nações. Esse novo cenário tornou as economias nacionais desorganizadas, secundárias, desregulamentadas, com forte ruptura do contrato social, segundo Touraine (1994, p.215). O autor citado complementa:

As três grandes tendências do nosso tempo, o triunfo de uma instrumentalidade que se tornou ação estratégica, a retirada para a vida privada e a globalização ecologista dos problemas propostos pela tecnologia, formam juntas um campo pós-social onde estão separadas as relações propriamente sociais, orientadas para outros atores sociais, as relações consigo mesmo e com a natureza. [...] A situação do pós-social é o produto de uma completa separação entre a instrumentalidade e o sentido; a primeira é gerida por empresas, econômicas ou políticas, em concorrência entre elas nos mercados; o segundo tornou-se puramente privado, subjetivo [...].

Podemos ainda acrescentar que as sociedades que não tiveram motivações internas na produção de tecnologias e no desenvolvimento industrial, e que ainda não transitaram para a era pós-industrial, foram agregadas ao sistema capitalista de ocupação desordenada dos espaços. Consolidou-se, assim, a divisão internacional do trabalho e a distinção de áreas, regiões e países, em função da extensão e da densidade da substituição dos objetos naturais e dos objetos culturais por objetos técnicos, conforme Santos (1997).

O processo de inserção das economias periféricas na lógica capitalista moderna, acentuado após a II Guerra Mundial, motivou a criação de condições favoráveis às estratégias de internacionalização da economia. O Brasil, seguindo a tradição econômico-cultural de abertura aos interesses externos, aplicou uma política de remoção dos obstáculos à expansão econômica internacional. Política que resultou na implantação de um modelo de desenvolvimento de base urbano-industrial. $\mathrm{O}$ rápido crescimento das cidades, a instalação de infra-estrutura para integrar o território nacional, viabilizando a produção e o comércio, inverteu o eixo organizacional brasileiro, como faz referência Carlos (1990, p.57):

O processo de industrialização, ao provocar profunda alteração na divisão social e espacial do trabalho, implica mudanças radicais na vida do homem. A aglomeração da população, dos meios de produção e capitais num determinado espaço, multiplica os pontos de concentração e produz uma rede articulada e hierarquizada.

A razão predominante no processo de urbanização e industrialização, na maioria das cidades brasileiras, ficou sujeita aos impulsos do crescimento econômico, sem qualquer preocupação com a manutenção das condições ambientais. A ausência de uma política de administração dos recursos renováveis e de um planejamento público eficaz levou à exploração incontrolada dos recursos, à deterioração dos ambientes naturais e à ocupação desordenada das áreas urbanas.

Nas cidades, a prática foi a de institucionalização do modelo de expansão irregular como solução habitacional para a população mais carente. A ausência de controles sociais sobre os mecanismos de valorização e especulação imobiliária causou a ampliação dos espaços urbanos em áreas sem infra-estrutura. Essas áreas se destinaram às populações mais pobres, sendo, na verdade, terrenos impróprios à ocupação ou, então, áreas destinadas à preservação. 


\section{Questão socioambiental}

A problemática ambiental no meio urbano pode estar ligada a condições decorrentes da expansão urbana, destacando-se a implantação de infra-estrutura básica sem controle, ou derivada de situações da própria urbanização, como poluição. A própria configuração da cidade pode causar problemas ambientais sérios, sempre que não se obedece a uma lógica de usos racionais dos espaços. É ponto pacífico entre os representantes dos governos e da própria sociedade civil, a necessidade de planejamento do meio urbano, pois as cidades, em escala mundial, oferecem exemplos de processos desenfreados de urbanização, fortemente relacionados à degradação socioambiental.

O crescimento urbano caracteriza-se por envolver uma multiplicidade de agentes e fatores do espaço em que o processo se concretiza. As cidades crescem a partir das contradições e da diversidade que diferentes lógicas sociais lhes emprestam. A problemática gerada nesse processo de urbanização reflete-se na organização e na ocupação do espaço, modificando as relações homem/sociedade e homem/ambiente natural. Nessa realidade incluem-se as desigualdades sociais, as migrações, o desemprego, a miséria, a especulação imobiliária e as exclusões no campo. Para Spósito (1988, p.27):

[...] cidade é o lugar do trabalho [...], mas também do lazer. É o lugar da produção e do consumo, do ir, do vir e do estar. É o lugar da ordem e da contra-ordem, dos sistemas econômicos e das lutas sociais. É o lugar das funções, mas também da natureza que se rebela. É comunicação e encontro, mas também isolamento, desencontro e procura. Enfim, a cidade é riqueza e pobreza, beleza e feiúra, é evolução, transformação e revolução, é unidade e diversidade, é contradição.

A origem dessas contradições é a forma de apropriação e transformação da natureza pelo homem. Para Casseti (1991), o modo como a sociedade se relaciona com a natureza está estreitamente vinculado à relação entre os próprios homens: o meio natural é o substrato em que as atividades humanas respondem pela organização do espaço, conforme padrões econômicos e sociais.

Em um primeiro momento, portanto, o desenvolvimento urbano esteve condicionado à lógica econômica global predominante, ou seja, ao desenvolvimento econômico e à geração de recursos obtidos a qualquer custo, sem preocupação com a questão socioambiental. Pode-se afirmar, numa segunda dimensão, que o modelo de planejamento adotado pelo Brasil preocupou-se, durante a expansão urbano-industrial, apenas com a implantação da infra-estrutura de interesse imediato, negligenciando a questão ambiental.

De acordo com Castells (1999), o movimento ambientalista multifacetado que surgiu a partir da década de 1960, na maior parte do mundo, principalmente nos Estados Unidos e no norte da Europa, representa o centro de uma discussão que reverte o pensamento sobre as formas de relação entre a economia, a sociedade e a natureza. Ainda, o autor citado, tratando do movimento ambiental na sociedade atual, sugere que a mobilização das comunidades locais em defesa de seu espaço, contrária à introdução de usos indesejáveis no meio ambiente, constitui a forma de ação ambiental que mais rapidamente vem se desenvolvendo nos últimos tempos. Isso talvez seja capaz de estabelecer a relação mais direta entre as preocupações imediatas das pessoas e as questões mais amplas de degradação ambiental e social. Esses movimentos visam assegurar aos cidadãos urbanos o direito à qualidade de vida, sendo, às vezes, contrários a interesses burocráticos ou corporativos. Além disso, questionam, de um lado, a tendência da localização de áreas para serem habitadas por minorias e populações de baixa renda e, de outro, a falta de transparência e de participação no processo decisório sobre a utilização do espaço. Conforme Castells (1999, p. 147),

Os cidadãos pertencentes a essa organização reivindicam maior democracia local, planejamento urbano responsável e senso de justiça quando da distribuição do ônus gerado pelo desenvolvimento urbano-industrial. [...] O conceito de justiça ambiental, como noção ampla que reafirma o valor da vida em todas as suas manifestações, contra os interesses de riqueza, poder e tecnologia, vem conquistando gradativamente as mentes e as políticas, à medida que o movimento ambientalista ingressa em um novo estágio de desenvolvimento. 
Em níveis local e regional, o movimento ambientalista organiza campanhas em defesa de novas formas de planejamento urbano e regional, de medidas de saúde pública e controle sobre as diversas formas de desenvolvimento. É esse pragmatismo, é essa atitude que dá ênfase à resolução das incompatibilidades, que exerce um poder de racionalidade nas decisões sobre as questões ambientais. Os resultados alcançados mostram que as organizações não-governamentais e outras organizações temáticas contribuem, decisivamente, para a formulação de políticas oficiais com relação à preservação dos ecossistemas naturais.

As ONGs conduziram a propostas de novas relações dos homens com a natureza, projetando outro modo de vida, outra cultura. A conscientização das questões ambientais deve-se, sem dúvida, a esse movimento, que fez nascer e desenvolver a primeira geração de políticas ambientais, baseadas na criação de órgãos governamentais, instituições públicas, privadas e normas e regulamentação. Essas políticas evoluíram no sentido da formulação de um instrumental normativo, destacando-se o licenciamento, o monitoramento e a fiscalização dos projetos e sua implementação.

A segunda geração de políticas ambientais, voltada para o fomento do desenvolvimento sustentável, exige, por parte das empresas, o uso de tecnologias apropriadas à segurança dos ecossistemas e, também, no processo de urbanização deve ser observado um ordenamento espacial do território compatível com os ambientes naturais. Essa nova etapa das políticas ambientais tem suporte em órgãos governamentais, destacando-se, no Brasil, a criação do Ministério do Meio Ambiente, em nível federal, e das fundações de proteção ambiental em nível estadual. Alguns municípios implantaram, em suas organizações estruturais, órgãos encarregados de ditar políticas preservacionistas.

\section{Planejamento e gestão}

Em nível global, a metropolização, os problemas ambientais e a complexidade e inter-relação dos problemas que afetam as cidades têm pressionado pela utilização de novos enfoques no planejamento urbano. Tais enfoques superam as limitações dos planos tradicionais. A maior parte dos planos elaborados na atualidade tem posto ênfase excessiva nos aspectos de competitividade econômica e não demonstra maior preocupação em explorar a via de desenvolvimento sustentável.

A reorientação das políticas que permeiam essa questão exige um planejamento técnico; porém, a sua implantação é um ato essencialmente político. O planejamento físico-territorial é uma evolução nos processos tradicionais de planejamento, motivado, em grande parte, pelo movimento ecológico. Em todo mundo, a oposição entre os conceitos de desenvolvimento para os pobres e a preservação para os ricos tem se transformado em um debate em diversos níveis, acerca da possibilidade real de desenvolvimento sustentado para cada país, cidade ou região.

Assim, a nova realidade nas relações sociedade/natureza estabeleceu as bases para o planejamento urbano e a construção de novos espaços produtivos, a partir de novas premissas. Criou-se, dessa maneira, o conceito de desenvolvimento sustentável, termo consagrado na Rio-92 (Conferência das Nações Unidas sobre Meio Ambiente e Desenvolvimento Humano), que passou a ser incorporado na elaboração de projetos em todas as categorias profissionais.

O Fórum Mundial de Cidades2 produziu um documento, endossado por prefeitos de todo o mundo, no qual ficaram explicitados os problemas ambientais, de dimensão global, gerados em cidades. As soluções adequadas a tais problemas devem, segundo o entendimento da maioria, serem sugeridas e aplicadas no âmbito das próprias cidades. A ação local é necessária para se encaminhar soluções globais. A importância local é decisiva para estabelecer as bases de poder e influência de poder, no encaminhamento das soluções de problemas criados pela expansão urbana e os projetos de criação de novos espaços para a produção, circulação e atividades de serviços. Essa ênfase foi bastante realçada na Rio-92 e, também, no Fórum Global,3 quando foram estabelecidos acordos institucionais sugeridos pelas organizações não-governamentais. Um desses acordos contempla a questão urba-

\footnotetext{
${ }^{2}$ Realizado em Curitiba, 1992.

${ }^{3}$ Reunião de ONGs realizada paralelamente à Rio-92.
} 
na e defende que as cidades primem pela justiça, democracia e sustentabilidade. Ribeiro (2000, p.237) produz a seguinte análise do documento do Fórum Global:

O documento propõe que a ação reguladora dos governos deverá voltar-se para criar condições de justiça, e, para tanto, as políticas públicas devem inverter prioridades e adotar o modelo de desenvolvimento sustentável, com participação crescente da sociedade civil, o que requer atitude de abertura dos governos e dos organismos internacionais... O tratado das ONGs sobre a questão urbana propõe, ainda, condicionar a produção do espaço às potencialidades do meio físico, ao equilíbrio ecológico e promover maior harmonia nas relações cidade-campo; propõe a gestão local imersa na sociedade, a tomada de decisão baseada em democracia participativa e não apenas nas forças do mercado. Essas manifestações das ONGs e dos governos locais pressupõem a atribuição de maiores responsabilidades aos municípios.

O mesmo autor sugere que diversas atividades de domínio externo, mas de âmbito e impacto locais, podem ser municipalizadas em termos de controle, fiscalização, licenciamento e, principalmente, de planejamento:

O eixo da gestão ambiental é a ação local que deve ser estimulada e apoiada pelos demais níveis de administração. Vasta agenda de temas e ações pode ser assumida diretamente pelas autoridades locais, com autonomia e sem dependência de outros níveis de governo. Essa agenda cobre temas que vão da fiscalização e do licenciamento ambiental, associado ao controle do uso do solo, até a educação ambiental formal, a consolidação de leis ambientais municipais e a gestão do espaço no âmbito local. Não fica descartada, no entanto, a participação de órgãos estaduais ou federais, como forma de melhor encaminhamento de soluções aos problemas ambientais. (RIBEIRO, 2000, p.250)

A Agenda 21, principal documento resultante da Rio-92, dedica o capítulo 7 à promoção do desenvolvimento sustentável dos assentamentos humanos, abordando a habitação, o manejo, a gestão e o planejamento sustentáveis, o saneamento ambiental, a energia, o transporte, a indústria da construção e as áreas sujeitas a desastres. Há assuntos relacionados à ciência e à transferência de tecnologia, aos aspectos institucionais e jurídicos que interferem na gestão ambiental e à necessidade de informações imprescindíveis para a tomada de decisões. Tratase de um conjunto de estratégias e proposições para alcançar o desenvolvimento sustentável, abordando de forma geral e, também, em segmentos específicos, as ações imediatas, de médio e de longo prazo.

Projetar e construir assentamentos humanos em harmonia com a natureza exige consciência da abrangência do tema e perspectiva no tempo. Exige também um tratamento sistêmico do ponto de vista do governo e da abordagem do urbano, já que as soluções para os problemas urbanos dependem de ações harmônicas de vários setores da administração pública, da iniciativa privada, das universidades e da sociedade civil. Guell (1997) estende ao campo do urbanismo a Teoria Geral dos Sistemas, com intenção de explicar e responder aos fenômenos urbanos, desenvolvendo um conceito de cidade e território, no qual estes são concebidos como sistemas funcionais. Nesse contexto, a cidade pode ser entendida como

[...] um complexo ecossistema de elementos e partes conectadas, onde atividades humanas estão entrelaçadas por comunicações que interatuam e o sistema evolui dinamicamente. Neste sistema, qualquer variação ou alteração, seja espacial ou estrutural, em uma de suas partes origina uma reação em cadeia que modifica ou influi nas outras partes do sistema. O dinamismo dos processos junto com a intensa interação das mudanças que tem lugar sobre o solo é que caracteriza a complexidade do enforque sistêmico no planejamento urbano. Em suma, o enfoque sistêmico persegue resolver os grandes desequilíbrios gerados pelo processo de urbanização através de uma organização dos sistemas de atividades urbanas, da conservação e da gestão dos recursos naturais e a melhora da qualidade de vida. Na mesma medida que uma cidade tem sido considerada um sistema funcional, o território no qual esta se insere configura sistemas superiores que estão intimamente relacionados em seus respectivos processos evolutivos. A necessidade de aplicar o enfoque sistêmico deriva da complexidade do funcionamento dos assentamentos. Se funcionarem de maneira independente, as políticas de desenvolvimento poderiam ser fragmentadas e implantadas de maneira isolada. Os assentamentos, no entanto, são geradores de intrincada rede de dependências e inter-relações necessárias ao desenvolvimento de condições favoráveis de habitabilidade. (GUELL, 1997, p.60) 
A organização espacial dos assentamentos urbanos pode-se entender melhor se estes contemplam uma perspectiva de conjunto, que considere tanto as características do ambiente natural e as necessidades físicas de expansão quanto as intenções e poderes que atuam em cada parcela. O enfoque sistêmico reconhece que os elementos (físicos e humanos) não são autônomos, que não atuam no vácuo. São imersos em uma complexa rede de interdependências, afetados uns pelos outros, e seu estado atual não pode ser entendido sem considerar a perspectiva de conjunto:

Assumindo as exposições anteriores, a cidade e sua área de influência imediata podem ser definidas como um sistema funcional, entendido como um conjunto de componentes relacionados entre si para a consecução de fins comuns. Em outras palavras, os indivíduos, as empresas e as instituições desenvolvem suas atividades em um sistema urbano do qual demandam uma série de recursos, infra-estruturas e serviços. Ademais, os sistemas urbanos existem em um determinado contexto (socioeconômico elou ambiental) e com ele interagem de maneira constante. (GUELL, 1997, p.61)

Guell (1997) destaca a utilização do conceito de planejamento estratégico como forma de colocar em prática o enfoque integrado e intersetorial da cidade. Esse conceito, extraído da prática militar, começou a ser utilizado como instrumento analítico e decisório no mundo empresarial a partir da segunda metade do século passado. Posteriormente, seu uso estendeu-se à gestão pública e, atualmente, também ao campo do planejamento e gestão urbana.

Esse autor afirma que a aplicação do planejamento estratégico ao âmbito do desenvolvimento urbano pode ser explicada por uma série de fenômenos significativos que exerceram influência sobre o status quo no planejamento urbano. Uma breve reflexão sobre as mudanças geopolíticas, econômicas, sociais, tecnológicas e administrativas conduz à identificação de implicações, tanto diretas quanto induzidas, sobre o desenvolvimento das cidades, exigindo respostas adequadas à nova situação.

Os diversos agentes sociais e econômicos, que tradicionalmente atuam na cidade, começam a exigir com insistência cumprimento de uma série de requerimentos de competitividade e habitabilidade como condição para sua permanência em uma área urbana determinada, obrigando os gestores públicos a considerar as exigências de ditos agentes e a contar com eles no momento de tomar decisões. A integração dos Estados-nações em blocos continentais e a abertura dos mercados comerciais em nível global têm dado lugar a uma aberta rivalidade entre cidades para captar recursos, postos de trabalho, turistas e ajudas públicas... A complexidade e inter-relação de problemas que afetam às cidades modernas têm obrigado à utilização de enfoques multidisciplinares e intersetoriais que superem as limitações dos planos setoriais tradicionais. (GUELL, 1997, p.10-11)

O autor citado considera que o dinamismo do entorno socioeconômico tem produzido, também, mudanças relevantes na atuação cotidiana do planejador e do gestor urbano, sintetizadas nos seguintes pontos: a) a descentralização das competências urbanísticas tem favorecido a adaptação da legislação urbanística às peculiaridades de cada região, principalmente, na área ambiental; b) o crescente peso dos movimentos sociais começa a atuar, mais fortemente, no processo de planejamento do desenvolvimento urbano, reivindicando com grande ênfase $o$ respeito à qualidade de vida; c) a crescente competição entre cidades para atrair atividades econômicas obriga os dirigentes a utilizarem todos os instrumentos a sua disposição, no sentido de garantir o processo de desenvolvimento; d) a incorporação de inovações tecnológicas na gestão urbana permite a automatização de procedimentos administrativos e de planejamento, com a utilização de instrumentos sofisticados que facilitam a tomada de decisão sobre operações urbanísticas de alta complexidade.

A crise do planejamento convencional no setor público, exposta por Giacomoni (1998), deve-se, em grande medida, à dificuldade de controlar as forças externas ao processo de crescimento urbano, à lenta assimilação das novas tecnologias, aos insuficientes conhecimentos da evolução dos processos sociais e à dificuldade para integrar com eficiência as equipes interdisciplinares. Essa situação tem propiciado a aparição de novos enfoques metodológicos e novos instrumentos de análise, que enfatizam os aspectos citados. 


\section{Utilização de técnicas de geoprocessamento no planejamento e gestão urbana}

O desenvolvimento da tecnologia da informação tornou disponível novos recursos que vieram modernizar os processos de planejamento e gestão urbana. Ao mesmo tempo, é possível desenvolver novos usos da informação, cada vez mais explorados pelas prefeituras brasileiras.

As técnicas convencionais de planejamento urbano, quando aplicadas para monitorar a expansão das cidades, não têm conseguido acompanhar a velocidade com que o fenômeno se efetua. Por isso, novos métodos, como as técnicas de geoprocessamento, empregam tecnologias mais adequadas, para detectar, em tempo quase real, a expansão urbana e as alterações ambientais decorrentes, contribuindo para maior eficiência da ação dos órgãos de planejamento.

Simão (1999) destaca que uma particularidade que distingue a informação para ordenamento do território é, sem dúvida, o seu componente espacial, assumindo-se que cerca de $80 \%$ das decisões tomadas por organizações da administração pública e local envolvem ou devem envolver o componente espacial, direta ou indiretamente.

Nesse sentido, os dados obtidos pelos sensores orbitais permitem, graças a suas resoluções temporal, espacial e espectral, captar tendências de expansão das áreas urbanas com precisão e registrar, periodicamente, as relações indiretas entre os fenômenos urbanos e seu ambiente regional. Os SIG representam uma potente ferramenta de apoio à decisão, através da integração de dados para análise, provenientes de diferentes fontes (sensores orbitais, GPS, mapas temáticos analógicos, informação alfanumérica) e da modelagem de diversos processos que ocorrem no mundo real. Burrough (1986) resume a utilidade da modelagem espacial como "ferramenta para acrescentar valor à informação", ou seja, gerar novos dados por meio de um processo estabelecido a partir de dados primários e modelos que descrevam o comportamento do mundo real em determinadas condições, obtendo, assim, resultados ou soluções para problemas espaciais complexos.

Um dos instrumentos mais importantes para o planejamento em áreas urbanas é a elaboração do plano diretor. Seu objetivo é disciplinar o uso do solo e preservar a qualidade de vida da população e, recentemente, a preservação dos ecossistemas. A implementação dos objetivos do plano emprega métodos diversos, envolvendo análises estatísticas, mapeamentos, zoneamentos, levantamentos cadastrais e pesquisa de campo, entre outros. Poucas vezes, todos esses métodos e informações, que representam custos elevados, são integrados para a obtenção de novos dados. Os métodos convencionais de análise tornam extremamente difícil essa integração e não raro a inviabilizam, em função do tempo necessário para efetuá-la.

Assim, os SIG representam uma ferramenta extremamente útil aos propósitos do planejamento municipal. Por reunirem um extenso conjunto de aplicativos para coletar, armazenar, recuperar, transformar e representar dados espaciais e, também, estatísticos ou textuais a eles relacionados, representam claramente um grande passo no sentido de uma maior racionalização no planejamento e no gerenciamento das administrações municipais.

Simão (1999), analisando os benefícios da adequação do Plano Diretor Municipal a um SIG, em diversos municípios de Portugal, destaca, além das inúmeras ferramentas para avaliação de decisões condizentes com o planejamento urbano, que os SIG permitem, também, a visão global da cidade e intersetorial da administração municipal:

Rapidamente, as prefeituras que implementaram sistemas de informação geográfica descobriram que um dos maiores benefícios na introdução desta tecnologia é a melhoria da própria organização. Esta optimização resulta de os SIG poderem interligar diferentes tipos de informação (receitas, saúde, educação, ouvidoria pública, patrimônio) pelas suas referências geográficas e ainda, facilitarem a comunicação e a partilha de informação, esta é recolhida e tratada uma vez e usada múltiplas vezes. Os sistemas de informação geográfica, pela sua natureza e concepção, podem integrar de forma eficiente toda a informação disponível e necessária à análise da problemática do ordenamento e gestão do território, assim como produzir nova informação geográfica e com ela gerar mais valias para essa análise. A sua implementação numa prefeitura corresponde à criação de uma poderosa ferramenta que permite 
disponibilizar e actualizar continuamente dados multisectoriais, facilmente relacionáveis num comum espaço geográfico.

A integração das informações de diversos setores da Prefeitura Municipal, relatada pelo autor, permite a atualização automática da base de informações espaciais, reduzindo os custos financeiros e o tempo, em virtude da entrada de dados ser feita através do SIG. Isso garante sua integridade, atualização on-line e eliminação da dupla entrada.

O município de União da Vitória, no Paraná, concluiu em 2001 o primeiro plano diretor georreferenciado (PDG) do Brasil. Sirorski, coordenador de Geoprocessamento do Paranacidade, ${ }^{4}$ explica que a principal vantagem em relação aos planos tradicionais é a facilidade de coleta, armazenamento e atualização de informações para o planejamento municipal:

A diferença entre o plano diretor tradicional e o georreferenciado é que este último é mais dinâmico e se baseia no desejo de obter uma imagem da cidade mais próxima da realidade, monitorando constantemente todo o processo de transformações físicas e sociais. Já o plano convencional apóia-se numa base de dados desatualizada e em permanente distanciamento da realidade. Trabalhando com dados sempre atualizados, o que não é possível com o plano diretor tradicional, poderemos acompanhar com mais eficiência o crescimento urbano e redefinir o uso do solo no município.

Outras vantagens destacadas pelos técnicos envolvidos no projeto são: a possibilidade de detectar as deficiências, riscos e processos de degradação ambiental; potencialidades econômicas e territoriais; controle e distribuição espacial da população e das atividades econômicas; uso e ocupação do solo urbano e análise de funcionamento da Lei de Zoneamento. O plano permite, ainda, o planejamento do transporte coletivo e do sistema viário urbano, a execução de análises de localização espacial de atividades econômicas, habitação e lazer, entre outros.

Um exemplo concreto de aplicação do PDG é sua a utilização pela prefeitura, para prever, com antecedência, os locais mais sujeitos a inundações, em função da cheia do rio Iguaçu, que banha o município. Em época de chuva, usando o SIG, a prefeitura pode prever o comportamento do rio, com até 24 horas de antecedência, com base na previsão do tempo do Simepar, ${ }^{5}$ no monitoramento de toda a bacia do rio Iguaçu. $\mathrm{O}$ trabalho possibilita a elaboração de mapas e auxilia a retirada das famílias de maneira lógica e racional. Além desse caso, a prefeitura tem pleno controle sobre todas as ocorrências na área urbana, evitando, por exemplo, a construção de imóveis em regiões com riscos de inundação.

Coelho e Pitanga (1982) empregaram técnicas de sensoriamento remoto para avaliar a evolução da cobertura e uso do solo na cidade do Rio de Janeiro, no período compreendido entre 1972 e 1980. Os estudos foram representados na forma de cartas temáticas, evidenciando a evolução espacial e dinâmica do processo de transformação no uso da terra naquela cidade. O resultado obtido viabilizou a implantação de medidas preventivas com vista ao restabelecimento do equilíbrio ecológico da região.

Farina (1999a) utilizou técnicas de sensoriamento remoto e SIG para avaliar o avanço de uma área de ocupação irregular, através de aterros, sobre a enseada da Mangueira, no município de Rio Grande (RS). Através de fotografias aéreas, de 1974, e imagens digitais de pequeno formato, de 1999, foi constatada, em ambiente SIG, a evolução temporal dos aterros realizados no período. Obteve-se, assim, a identificação e a quantificação do avanço de terras emersas na enseada, representado por meio de mapas. O estudo serviu de base para a elaboração do diagnóstico socioambiental e para o encaminhamento à Prefeitura Municipal de propostas de recuperação das condições socioambientais (Farina, 1999b).

Farina (2003) elaborou uma metodologia em ambiente SIG para planejamento da expansão urbana. A modelagem do mundo real no SIG, através da criação de planos de informação (PI), foi a base para espacializar e analisar as variáveis pertinentes ao estudo. Dessa forma, são gerados PIs primários de cobertura vegetal, hidrografia, área urbana, e PIs derivados distância à área urbana, distância à hidrografia, geologia, adequabilidade em

\footnotetext{
${ }^{4}$ Serviço Social Autônomo Paranacidade: órgão do governo do estado do Paraná.

${ }^{5}$ Sistema Meteorológico do Paraná
} 
relação à hidrografia, entre outros. Os PIs gerados foram cruzados utilizando métodos de análise espacial, obtendo-se como resultado desses procedimentos, um mapa temático final contendo classes de adequabilidade à expansão urbana. Com a finalidade de avaliar a adequação da metodologia desenvolvida, foi selecionada uma área teste, situada no município de Rio Grande. A metodologia proposta é, então, aplicada a essa área, resultando em um mapa temático contendo as classes de adequabilidade à expansão urbana para o município do Rio Grande. Esse produto pode ser utilizado pela administração municipal para fins de planejamento urbano. A base de dados gerada poderá ser modelada para atender a diversas aplicações relacionadas ao planejamento territorial, como seleção de áreas adequadas para aterros sanitários, localização de indústrias, avaliação de impactos ambientais.

Niero e Foresti (1982) utilizaram imagens orbitais no monitoramento da expansão urbana, em áreas de proteção dos recursos hídricos na Região Metropolitana de São Paulo. Através de dados obtidos pelo sistema Landsat (MSS, RBV), monitoraram a área urbana, analisando a resposta espectral da franja rural-urbana para diferentes períodos sazonais. Obtiveram o mapeamento e a avaliação da expansão urbana no período de 1977 a 1979. A aplicação de técnicas de interpretação visual e digital aos dados revelou taxa de crescimento de $29 \%$ no período referido.

Barredo (1996) expõe a utilização de técnicas de geoprocessamento para a criação do Sistema de Informação Ambiental da Bacia do Lago Valencia, na Venezuela. Através de dados provenientes de sensores orbitais, GPS, cartas temáticas, integrados e manipulados em um SIG, foram desenvolvidos estudos, visando detectar, mitigar e prevenir problemas ambientais, advindos de conflitos de diferentes usos do solo, como a urbanização, a agricultura e outras atividades antrópicas, com a aptidão natural da região.

Lo e Shipman (1990) utilizaram SIG para avaliar os efeitos da urbanização em Tuen Mun, New Territories, Hong Kong, através da integração de fotografias aéreas, cartas topográficas e mapas geológicos. Os autores destacaram a capacidade da metodologia empregada para detectar as mudanças no uso do solo e o impacto ambiental decorrente. Na China, o SIG, atualmente, é extensivamente usado pelos órgãos do governo, em um amplo leque de aplicações, que incluem análise de recursos ambientais, planejamento de uso do solo, análise locacional, avaliação de impostos, planejamento de infra-estrutura, análise de bens imóveis, marketing, análise demográfica, estudos de hábitats e análise arqueológica.

Hannessee e Defries (1999), analisando a fortificação da tecnologia SIG no estado de Maryland, descrevem diversos casos de aplicação do SIG. Os autores destacam o projeto Corredor Verde, estabelecido para definir áreas de preservação ao longo de fragmentos de floresta, no condado de Baltimore. A metodologia foi desenvolvida para avaliar o potencial de desmatamento, em função do avanço da urbanização sobre áreas ecologicamente sensíveis, e definir as áreas vulneráveis ao processo de urbanização. A base de dados foi gerada pela classificação digital de imagens Landsat e Spot, resultando nos planos de informação de cobertura florestal, hidrografia e uso da terra. Outros dados, como delimitação das bacias hidrográficas, foram obtidos do levantamento geológico dos Estados Unidos. A implementação da metodologia no SIG determinou graus de vulnerabilidade dos ecossistemas em relação ao avanço da urbanização. Esse estudo foi utilizado pelo governo para a criação dos Corredores Verdes, com regime legal específico, normatizando os usos do solo nas proximidades dos corredores.

Em outro exemplo citado pelos autores, o avanço incontrolado da indústria química na área do porto de Baltimore, em 1998, resultou em protestos dos cidadãos residentes nas proximidades, exigindo a reparação e proteção para seus lares. O Departamento do Meio Ambiente de Maryland utilizou mapas gerados em SIG para determinar, com eficácia, a exata localização de residências em risco. Através desse estudo, o governo estabeleceu a remoção e a indenização dos moradores em risco e o uso do solo foi definido estritamente para a indústria pesada.

A utilização dessas tecnologias tem contribuído muito em relação ao planejamento urbano, ao uso do solo e à conservação dos recursos naturais. O emprego das técnicas de geoprocessamento como ferramenta de avaliação nas prefeituras brasileiras, no entanto, ainda é reduzido quando comparado ao seu potencial. 
A reunião de prefeitos dos municípios do estado do Paraná, ocorrida no Encontro Mundial de Cidades, discutiu a importância do planejamento prévio do território, antes de seu efetivo aproveitamento econômico. O documento resultante recomenda a ampliação da participação de especialistas em geoprocessamento nos esforços de planejamento, de implementação de políticas públicas e na formulação de estratégias no campo da administração dos recursos naturais.

\section{Conclusão}

O planejamento setorial das cidades não favorece a visão global dos problemas urbanos e a formulação de um modelo integrado para seu desenvolvimento futuro. Na atualidade, a grande ênfase é para a integração dos planos setoriais, assim como a coordenação horizontal e vertical entre os diversos níveis territoriais e administrativos do planejamento.

No passado, os planos baseavam-se em necessidades imediatas, que caracterizavam uma ação administrativa correspondente à oferta urbana (solo, infra-estrutura, equipamentos); hoje, ao contrário, a consideração fundamental é pela demanda urbana (cidadãos, empresas, turistas). Os planos colocavam ênfase excessiva nos aspectos de infra-estrutura e uso do solo, sem levarem em conta os critérios de desenvolvimento sustentável. A implantação de políticas de ordenação territorial, na atualidade, passou a requerer a configuração de lugares e regiões, visando ao melhor equacionamento das questões urbanas.

Portanto, o planejamento normativo e centralizado aplicado durante os anos 1960 e 1970 evoluiu para o uso de técnicas fundamentadas nos conceitos e paradigmas da gestão estratégica. A aplicação do planejamento estratégico e das técnicas de geoprocessamento na gestão urbana pode ser definida como uma forma sistemática de dirigir as mudanças e criar o melhor futuro possível para uma cidade e assenta as bases de uma atuação integrada em longo prazo, estabelece um sistema contínuo de tomada de decisões que comporta riscos, identifica cursos de ação específicos, formula indicadores de acompanhamento sobre os resultados e envolve os agentes sociais e econômicos locais ao longo de todo o processo (GUELL, 1997).

Os problemas atuais e os acontecimentos futuros da cidade não podem ser resolvidos apenas pelas tradicionais propostas urbanísticas. Para viabilizar operações reestruturadoras do tecido físico, econômico e social de uma aglomeração urbana é necessária uma política mais ampla com objetivos estratégicos intersetoriais. É essencial um planejamento que vise orientar e articular as ações setoriais, com um programa global definido.

Para Guell (1997), isso é possível através da aplicação do planejamento estratégico nas cidades. Outra característica marcante do planejamento estratégico é flexibilidade de decisão. Os planos urbanísticos convencionais, geralmente, são formulados para atender às exigências legais relacionadas com o uso do solo e com a gestão do crescimento. Como consequiência, os planos urbanísticos apresentam uma rigidez que se choca com o processo político e que requer flexibilidade para abordar problemas muito complexos com alto grau de incerteza. Pelo contrário, os planos estratégicos podem prover uma ponte entre exigências legais relativamente rígidas e as decisões políticas que demandam maior flexibilidade.

No Brasil, essa nova forma de pensar encontra resistência à aplicação prática nas administrações municipais. Isso ocorre, em grande medida, pela resistência das estruturas tradicionais e pela reprodução de planos superados, geralmente, concebidos para outras realidades. A modernização da administração pública é um elementochave para a organização racional do território urbano e das suas funcionalidades, já que a organização e a sistemática das funções urbanas dependem, em grande proporção, do aparato administrativo que a sustenta. Isso implica não mais reproduzir os modelos vigentes de administração municipal, mas considerar a participação da comunidade nos processos decisórios e renovar a estrutura das organizações públicas com as técnicas atuais.

Reportando-se ao documento resultante da Rio-92, a Agenda 21, o planejamento estratégico exige que cada município estabeleça o meio ambiente como a variável principal à adoção de princípios sustentáveis nas políticas setoriais e no processo de tomada de decisões.

A produção e a aplicação de conhecimentos sobre os impactos ambientais no meio urbano são tarefas necessárias para reduzir as pressões sobre os ecossistemas. Portanto, a competência, o saber e o conhecimento técnico e 
científico são fundamentais para a gestão ambiental. Na sociedade da informação e do conhecimento, a pesquisa e o estudo têm o mérito de reduzir a margem de erro na tomada de decisão.

\section{Referências}

BARREDO, J. I. Sistemas de información geográfica y evaluación multicriterio en la ordenación del territorio. Madrid: RA-MA, 1996.

BOSQUE, J. S. Sistemas de información geográfica. Madrid: Rialp, 1997.

BURROUGH, P. A. Principles of geographical information systems for land resources assessment. New York: Oxford University Press, 1986.

CARLOS, A. F. A. Espaço e indústria. São Paulo: Contexto, 1990.

CASSETI, V. Ambiente e apropriação do relevo. São Paulo: Contexto, 1991.

CASTELLS, M. 0 poder da identidade. São Paulo: Paz e Terra, 1999.

COELHO, D.; PITANGA, J. F. S. Evolução do uso e cobertura do solo da cidade do Rio de Janeiro: 1972-1980. In: SIMPÓSIO BRASILEIRO DE SENSORIAMENTO REMOTO, 1982, Brasília, DF. Anais... Brasilia, DF, 1982. v.3, p.10-14.

FARINA. F. C. Utilização de técnicas de sensoriamento e sistemas de informação geográfica para a definição de áreas aterradas marginais à enseada da Mangueira. Trabalho de graduação, Departamento de Geociências, FURG, Rio Grande, RS, 1999a.

Diagnóstico socioambiental das áreas adjacentes à enseada Mangueira. Relatório técnico. Prefeitura Municipal do Rio Grande, Rio Grande, RS, $1999 \mathrm{~b}$.

Utilização de técnicas de geoprocessamento para seleção de áreas adequadas à expansão urbana. Caso do municipio de Rio Grande, RS. Tese (Mestrado - Programa de Pós-Graduação em Geografia), Instituto de Geociências, Universidade Federal do Rio Grande do Sul, Porto Alegre, 2003.

GIACOMONI, J. Orçamento tradicional e orçamento participativo: o caso de Porto Alegre. In: FACHIM, R.; CHANLAT. (Org.). Governo municipal na América Latina: inovações e perplexidades. Porto Alegre: UFRGS, 1998.

GUELL, J. M. F. Planificación estratégica de ciudades. Barcelona: Editorial Gustavo Gili, 1997.

HANNESSEE, L.; DEFRIES. V. Entrenchment of GIS technology for enterprise solutions in Maryland's State and local government. Photogrammetric Engineering \&t Remote Sensing, v.65, n.11, p.1277-1286, 1999.

LO, C. P.; SHIPMAN, R. L.. A GIS approach to land-use change dynamics detection. Photogrametric Engineering and Remote Sensing, v 56, n.11, p.342-350, 1990.

NIERO, M. FORESTI,C. Utilização de dados Landsat no monitoramento da expansão urbana da Grande São Paulo, em áreas de proteção aos mananciais. In: SIMPÓSIO BRASILEIRO DE SENSORIAMENTO REMOTO, 1982, Brasília, DF. Anais... Brasília, 1982. v.3, p.863-67.

PARANACIDADE. Paraná: pioneiro na adoção do Plano Diretor Georreferenciado. Programa Paraná Urbano, Curitiba. Disponível em: <http://www.paranacidade.org.br >. Acesso em: dez. 2001.

RIBEIRO, M. A. Ecologizar: Pensando o ambiente humano. Belo Horizonte: RONA, 2000.

SANTOS, M. A natureza do espaço. Técnica e tempo. Razão e emoção. São Paulo: Hucitec, 1997a.

SIMÃO, A. J. V. Os sistemas de informação geográfica na gestão dos planos municipais de ordenamento territorial. Relatório técnico. Coimbra: Montemor-o Velho, 1999.

SPÓSITO, M. E. B.. Capitalismo e urbanização. São Paulo: Contexto, 1988.

TOURAINE, A. Crítica da modernidade. Rio de Janeiro: Vozes, 1994. 